\title{
Association of Peripheral Total and Differential Leukocyte Counts with Obesity- Related Complications in Young Adults
}

\author{
Aya Yoshimura $^{a}$ Shunsuke Ohnishi ${ }^{a}$ b Chieko Orito $^{a} \quad$ Yukako Kawahara $^{a}$ \\ Hiroyo Takasakic Hiroshi Takedac, d Naoya Sakamotob \\ Satoshi Hashino ${ }^{a}$ \\ ${ }^{a}$ Health Care Center, Hokkaido University, Sapporo, Japan; ${ }^{b}$ Department of \\ Gastroenterology and Hepatology, Hokkaido University Graduate School of Medicine, \\ Sapporo, Japan; ' Nutrition Center, Hokkaido University Hospital, Sapporo, Japan; \\ d Laboratory of Pathophysiology and Therapeutics, Faculty of Pharmaceutical Sciences, \\ Hokkaido University, Sapporo, Japan
}

\author{
Key Words \\ Inflammation · Obesity $\cdot$ Insulin resistance $\cdot$ Dyslipidemia $\cdot$ Body fat
}

\begin{abstract}
Objective: Obesity has been demonstrated to be associated with elevated leukocytes in adults and children. This study assessed the associations between peripheral total and differential leukocyte counts and obesity-related complications in young adults. Methods: 12 obese (median age 21.5 (range 19-28) years, median BMI 35.7 (range 32.0-44.9) $\mathrm{kg} / \mathrm{m}^{2}$ ) and 11 normal (median age 23 (range 18-27) years, median BMI 19.5 (range 18.1-21.7) kg/m²) adults were enrolled. Complete blood count and serum levels of liver enzymes, fasting blood glucose, insulin and lipids were measured, and the homeostasis model assessment of insulin resistance was calculated. Fat mass was calculated using a bioimpedance analysis device, and ultrasonography was performed to measure fat thickness and to detect fatty change of the liver. Results: Total leukocyte and monocyte counts were significantly increased in obese young adults. Total leukocyte count was associated with liver enzyme levels, insulin resistance as well as visceral and subcutaneous fat thickness. Neutrophil count was associated with insulin resistance. Lymphocyte count was associated with serum liver enzymes, insulin resistance, and dyslipidemia. Monocyte count was associated with serum liver enzyme, insulin resistance, visceral and subcutaneous fat thickness, body fat mass, and percentage body fat. Conclusion: The results of this study suggest that chronic low-grade systemic inflammation is associated with obesity-related complications such as nonalcoholic fatty liver disease, insulin resistance, and dyslipidemia in young adults.


Yoshimura et al.: Association of Peripheral Total and Differential Leukocyte Counts with Obesity-Related Complications in Young Adults

\section{Introduction}

Obesity is one of the leading causes of morbidity and mortality in both adults and children, and its prevalence is increasing in the younger population [1,2]. Because obesity is associated with type 2 diabetes, hypertension, coronary heart disease, and certain forms of cancer, early prevention of obesity has assumed great importance. Recently, it has become clear that obesity is also associated with immunological abnormalities [3]. Inflammatory cells such as lymphocytes and macrophages have been shown to infiltrate into the adipose tissue in obese humans, and proinflammatory cytokines such as tumor necrosis factor $\alpha$ (TNF- $\alpha$ ) and interleukin 6 (IL-6) are produced by those inflammatory cells and adipocytes, causing chronic lowgrade systemic inflammation $[2,4,5]$.

Studies in the last few decades have demonstrated that obese adults and children have elevated total leukocytes [6-14], the majority of which appear to be related to monocytes [15]; however, other types of leukocytes - such as lymphocytes and neutrophils - may also be elevated [9]. It is not known whether the number of these inflammatory cells in circulation is associated with obesity-related complications such as nonalcoholic fatty liver disease (NAFLD), insulin resistance, and dyslipidemia in young adults.

We therefore measured serum liver enzyme and lipid levels, insulin resistance, and fat volume and investigated the association of peripheral total and differential leukocyte counts with obesity-related complications in young adults.

\section{Material and Methods}

\section{Subjects}

12 students, each with a BMI of $\geq 35 \mathrm{~kg} / \mathrm{m}^{2}$ (obese group), were recruited from the participants at the 2013 annual health check-up held at the Health Care Center, Hokkaido University, Sapporo, Japan. In addition, 11 age-matched students, each with a BMI of $20-22 \mathrm{~kg} / \mathrm{m}^{2}$ (control group), were recruited. None of the subjects were on any medications, none were smokers, and all were negative for hepatitis B surface antigen, anti-hepatitis C virus antibody and anti-nuclear antigen, suggestive that they are free from chronic viral hepatitis and autoimmune hepatitis. Their alcohol ingestion was $<140 \mathrm{~g} / \mathrm{week}$. This study was approved by the Ethics Committee of Hokkaido University Graduate School of Medicine. After the purpose of the study had been explained to all subjects, written informed consent was obtained according to the tenets of the 1975 Declaration of Helsinki.

\section{Blood Examination}

Blood samples were collected into ethylene diamine tetraacetic acid-dipotassium salt dihydrate (EDTA-2K) tubes, sodium fluoride (NaF) tubes, and in plain polystyrene tubes after overnight fasting. Complete blood count and the subtype fractions of leukocytes were analyzed by an automated blood cell counter (XS-1000i; Sysmex, Kobe, Japan). Other biochemical measurements were performed at SRL Inc. (Tokyo, Japan), and the following data were collected: total bilirubin (T-Bil, vanadate oxidase method, CV\% = 1.351), aspartate aminotransferase (AST, standardization-adjusted ultraviolet method, CV\% $=1.262$ ), alanine aminotransferase (ALT, standardization-adjusted ultraviolet method, CV\% $=1.309$ ), $\gamma$-glutamyl transpeptidase ( $\gamma$-GTP, L-glutamyl-3-carboxy-4-nitroanilide substrate method, CV\% = 1.895), cholinesterase (ChE, Japan Society of Clinical Chemistry (JSCC) method, CV\% = 0.791), fasting blood glucose (FBG, hexokinase method, $\mathrm{CV} \%=1.12)$, hemoglobin $\mathrm{A} 1 \mathrm{c}(\mathrm{HbA1c}$, latex agglutination inhibition method, $\mathrm{CV} \%=$ 2.33), insulin (chemiluminescent enzyme immunoassay, CV\% = 4.25), total cholesterol ( $\mathrm{T}-\mathrm{CHO}$, cholesterol dehydrogenase-ultraviolet method, CV\% = 1.144), high-density lipoprotein cholesterol (HDL-C, selective inhibition method, $C V \%=1.571$ ), low-density lipoprotein cholesterol (LDL-C, direct method, CV = 2.504), triglyceride (TG, glycerol kinase-glycerol-3-phosphate oxidase-peroxidase method, CV\% = 1.134), total protein (TP, Biuret method, CV\% = 1.622), albumin (Alb, modified bromocresol purple method, CV\% = 1.348 ), amylase (AMY, JSCC method, CV\% = 1.174), blood urea nitrogen (BUN, urease method, $C V \%=1.173$ ), creatinine (Cre, enzymatic method, CV\% = 1.304), uric acid (UA, uricase-peroxidase method, CV\% $=1.253$ ), 
Yoshimura et al.: Association of Peripheral Total and Differential Leukocyte Counts with Obesity-Related Complications in Young Adults

and C-reactive protein (CRP, latex immunonephelometric method, CV\% = 1.821). All tests were performed on the day of blood collection. The insulin resistance index was calculated from the homeostasis model assessment of insulin resistance (HOMA-IR) using the following equation: (fasting insulin in $\mu \mathrm{U} / \mathrm{l}) \times(\mathrm{FBG}$ in $\mathrm{mmol} / \mathrm{l}) / 22.5$ [16].

\section{Body Composition Measurement}

Body composition, including body fat mass and percentage body fat, was calculated using a bioimpedance analysis device (InBody S20; Biospace, Seoul, South Korea), which appears to be noninvasive and accurate for evaluating body composition [17].

\section{Ultrasonography}

Ultrasonography was performed for all subjects in the supine position using a probe located $1 \mathrm{~cm}$ above the umbilical scar on the abdominal midline (LOGIQ S7, GE Healthcare). Subcutaneous fat thickness was measured as the distance $(\mathrm{cm})$ between the skin and the external surface of the rectus abdominis muscle, and visceral fat thickness was measured as the distance between the internal surface of the rectus abdominis muscle and the anterior wall of the aorta [18]. Fatty liver was defined on the basis of a combination of liverkidney contrast (bright liver) and vascular blurring [19].

\section{Statistical Analyses}

Data are expressed as median with range. Differences in each parameter between the obese and control groups were examined for statistical significance using a nonparametric Mann-Whitney test. Spearman's correlation coefficient and linear regression were used to assess the simple relationship between the variables. The significance threshold was set at $\mathrm{p}<0.05$.

\section{Results}

The characteristics of 11 control and 12 obese subjects are shown in table 1 . Both groups had a similar age distribution $(p=0.126)$. The obese group included only males, whereas 4 out of 11 subjects in the control group were female. Fatty change of the liver was not observed in the control group, whereas 9 out of 12 subjects in the obese group exhibited fatty change of the liver on ultrasonography and were diagnosed with NAFLD. Body composition measurement using a bioimpedance analysis device demonstrated that body fat mass and percentage body fat were significantly higher in the obese group than in the control group. Furthermore, visceral fat thickness and subcutaneous fat thickness as measured by ultrasonography were significantly increased in the obese group compared with those in the control group. The obese group exhibited significantly higher serum levels of liver enzymes such as AST, ALT, $\gamma$-GTP, and ChE. Serum insulin, HOMA-IR, LDL-C, TG, UA, and CRP levels were significantly higher in the obese group than in the control group. On the other hand, Alb, AMY, and HDL-C levels were significantly higher in the control group than in the obese group. FBG, HbA1c, T-Bil, T-CHO, TP, BUN, and Cre levels were comparable between groups.

The complete blood count of the subjects is presented in table 2. The peripheral erythrocyte and total leukocyte counts were significantly higher in the obese group than in the control group. Particularly, significant increases were noted in the monocyte count in the obese group compared with those in the control group. There was no significant difference in peripheral neutrophil, lymphocyte as well as eosinophil and basophil counts between groups.

We then analyzed whether peripheral total leukocyte, neutrophil, lymphocyte, and monocyte counts correlated with the serum levels of liver enzymes in all 23 subjects. A significant positive correlation was found between total leukocyte, lymphocyte or monocyte counts and AST, ALT, $\gamma$-GTP, and ChE levels (fig. 1). 
Yoshimura et al.: Association of Peripheral Total and Differential Leukocyte Counts with Obesity-Related Complications in Young Adults

Table 1. Subject characteristics and biochemical data

\begin{tabular}{|c|c|c|}
\hline & Control group $(\mathrm{n}=11)$ & Obese group $(\mathrm{n}=12)$ \\
\hline Male/female & $7 / 4$ & $12 / 0$ \\
\hline Age, years & $23(18-27)$ & $21.5(19-28)$ \\
\hline BMI, $\mathrm{kg} / \mathrm{m}^{2}$ & $19.5(18.1-21.7)$ & $35.7(32.0-44.9)^{* * *}$ \\
\hline $\mathrm{BFM}, \mathrm{kg}$ & $8.2(6.0-14.9)$ & $41.8(26.6-63.0)^{* * *}$ \\
\hline $\mathrm{PBF}, \%$ & $14.6(10.6-29.8)$ & $39.1(26.4-48.6)^{* * *}$ \\
\hline Visceral fat thickness, mm & $23.2(17.2-47.3)$ & $69.4(39.8-92.1)^{* * *}$ \\
\hline Subcutaneous fat thickness, $\mathrm{mm}$ & $5.4(3.2-9.9)$ & $15.8(11.5-29.8)^{* * *}$ \\
\hline Existence of fatty liver $(+/-)$ & $0 / 11$ & $9 / 3$ \\
\hline T-Bil, $\mu \mathrm{mol} / \mathrm{l}$ & $15.4(5.1-34.2)$ & $13.7(6.8-35.9)$ \\
\hline AST, U/l & $17(14-35)$ & $25(15-89)^{* *}$ \\
\hline ALT, U/l & $12(9-42)$ & $39.5(13-189)^{* * *}$ \\
\hline$\gamma$-GTP, U/l & $17(11-28)$ & $33.5(14-133)^{* *}$ \\
\hline ChE, U/l & $276(196-345)$ & $406(306-479)^{* * *}$ \\
\hline $\mathrm{FBG}, \mathrm{mmol} / \mathrm{l}$ & $4.6(4.3-5.1)$ & $4.8(4.2-5.3)$ \\
\hline $\mathrm{HbA} 1 \mathrm{c}, \%$ & $5.0(4.7-5.9)$ & $5.1(4.5-5.6)$ \\
\hline Insulin, $\mu \mathrm{IU} / \mathrm{ml}$ & $3.1(2.2-6.4)$ & $12.1(6.3-32.4)^{* * *}$ \\
\hline HOMA-IR & $0.7(0.4-1.5)$ & $2.6(1.5-6.9)^{* * *}$ \\
\hline T-CHO, mmol/l & $4.3(3.7-5.5)$ & $4.9(3.6-10.5)$ \\
\hline HDL-C, mmol/l & $1.6(1.3-2.5)$ & $1.1(0.8-1.3)^{* * *}$ \\
\hline LDL-C, mmol/l & $2.2(1.2-3.5)$ & $3.4(2.3-8.1)^{* *}$ \\
\hline $\mathrm{TG}, \mathrm{mmol} / \mathrm{l}$ & $0.5(0.4-1.7)$ & $1.2(0.5-3.6)^{* *}$ \\
\hline $\mathrm{TP}, \mathrm{g} / \mathrm{l}$ & $73(69-82)$ & $73(68-79)$ \\
\hline Alb, g/l & $47(41-49)$ & $44(40-48) *$ \\
\hline $\mathrm{AMY}, \mathrm{U} / \mathrm{l}$ & $74(59-229)$ & $57.5(36-75) * *$ \\
\hline BUN, mmol/l & $4.2(3.3-5.7)$ & $3.8(2.7-5.2)$ \\
\hline Cre, $\mu \mathrm{mol} / \mathrm{l}$ & $71.6(47.7-84.9)$ & $67.6(60.1-91.1)$ \\
\hline $\mathrm{UA}, \mu \mathrm{mol} / \mathrm{l}$ & $350.9(148.7-452.0)$ & $443.1(232.0-535.3)^{* *}$ \\
\hline CRP, mg/l & $0.2(0.0-4.8)$ & $1.6(0.2-28.1)^{* *}$ \\
\hline
\end{tabular}

$\mathrm{BFM}=$ Body fat mass; $\mathrm{PBF}=$ percent body fat; $\mathrm{T}-\mathrm{Bil}=$ total bilirubin; $\mathrm{AST}=$ aspartate aminotransferase; $\mathrm{ALT}=$ alanine aminotransferase; $\gamma$-GTP $=\gamma$-glutamyl transpeptidase; $\mathrm{ChE}=$ cholinesterase; $\mathrm{FBG}=$ fasting blood glucose; HbA1c = hemoglobin A1c; HOMA-IR = homeostasis model assessment of insulin resistance; $\mathrm{T}-\mathrm{CHO}=$ total cholesterol; HDL-C = high-density lipoprotein cholesterol; LDL-C = low-density lipoprotein cholesterol; $\mathrm{TG}$ = triglyceride; $\mathrm{TP}$ = total protein; $\mathrm{Alb}=$ albumin; $\mathrm{AMY}=$ amylase; $\mathrm{BUN}=$ blood urea nitrogen; Cre = creatinine; $\mathrm{UA}=$ uric acid; $\mathrm{CRP}=\mathrm{C}$-reactive protein.

${ }^{*} \mathrm{p}<0.05,{ }^{* *} \mathrm{p}<0.01,{ }^{* * *} \mathrm{p}<0.001$ versus the control group.

Although peripheral total leukocyte, neutrophil, lymphocyte, and monocyte counts did not correlate with FBG and HbA1c (fig. 2A, B) levels, they significantly correlated with insulin levels and HOMA-IR (fig. 2C, D).

Peripheral total leukocyte, neutrophil,lymphocyte. and monocyte counts did not correlate with T-CHO levels (fig. 3A); however, lymphocyte and monocyte counts positively correlated with LDL-C levels and negatively correlated with HDL-C levels (fig. 3B, C). Peripheral lymphocyte count significantly correlated with TG levels, but total leukocyte, neutrophil, and monocyte counts did not (fig. 3D).

Peripheral monocyte count, but not lymphocyte count, significantly correlated with visceral and subcutaneous fat thickness as measured by ultrasonography (fig. 4A, B) and with body fat mass and percentage body fat as calculated by a bioimpedance analysis device (fig. 4C, D). 
Yoshimura et al.: Association of Peripheral Total and Differential Leukocyte Counts with Obesity-Related Complications in Young Adults

Table 2. Complete blood count of subjects

\begin{tabular}{cll}
\hline & \multicolumn{1}{l}{ Control group $(\mathrm{n}=11)$} & Obese group $(\mathrm{n}=12)$ \\
\hline Erythrocytes $\times 10^{4} / \mu \mathrm{l}$ & $499(420-566)$ & $552(473-635)^{*}$ \\
$\mathrm{Hb}, \mathrm{g} / \mathrm{dl}$ & $15.1(11.5-17.1)$ & $16.3(13.8-17.8)$ \\
$\mathrm{Ht}, \%$ & $44.0(34.5-48.7)$ & $46.8(40.7-51.2)$ \\
$\mathrm{MCV}, \mathrm{fl}$ & $89.7(76.8-93.1)$ & $85.5(80.6-92.1)$ \\
$\mathrm{MCH}, \mathrm{pg}$ & $30.3(25.6-33.0)$ & $29.4(27.7-32.5)$ \\
$\mathrm{MCHC}, \%$ & $34.5(32.1-36.5)$ & $34.8(33.8-36.2)$ \\
Total leukocytes $/ \mu \mathrm{l}$ & $5,060(3,480-11,090)$ & $7,120(4,090-11,600)^{*}$ \\
Neutrophils $/ \mu \mathrm{l}$ & $3,106(2,168-7,995)$ & $4649(1,950-8,827)$ \\
Lymphocytes $/ \mu \mathrm{l}$ & $1,788(890-2,439)$ & $2,141(1,587-3,161)$ \\
Monocytes $/ \mu \mathrm{l}$ & $298(197-487)$ & $419(269-552)^{* *}$ \\
Eosinophils $/ \mu \mathrm{l}$ & $130(32-391)$ & $152(37-209)$ \\
Basophils $/ \mu \mathrm{l}$ & $32(19-44)$ & $29(8-42)$ \\
Plt $\times 10^{4} / \mu \mathrm{l}$ & $22.9(17.2-32.4)$ & $26.1(20.2-34.7)$ \\
\hline
\end{tabular}

$\mathrm{Hb}=$ Hemoglobin; $\mathrm{Ht}=$ hematocrit; $\mathrm{MCV}=$ mean corpuscular volume; $\mathrm{MCH}=$ mean corpuscular hemoglobin concentration; $\mathrm{MCHC}=$ mean cell hemoglobin concentration; Plt = platelets.

${ }^{*} \mathrm{p}<0.05,{ }^{* *} \mathrm{p}<0.01$ versus the control group.

\section{Discussion}

In this study, we analyzed 12 obese and 11 normal (control) young adults and demonstrated that i) peripheral total leukocyte and monocyte counts increased significantly in obese young adults, ii) total leukocyte count was associated with liver enzyme levels, insulin resistance, and visceral and subcutaneous fat thickness in young adults, iii) neutrophil count was associated with insulin resistance, iv) lymphocyte count was associated with serum liver enzymes, insulin resistance and dyslipidemia, and v) monocyte count was associated with serum liver enzyme, insulin resistance, visceral and subcutaneous fat thickness as well as body fat mass and percentage body fat.

Peripheral total leukocyte count was reportedly elevated in patients with NAFLD [20], and the presence of NAFLD was significantly associated with higher peripheral total leukocyte and monocyte counts [21]. In addition, a recent meta-analysis of 20 studies demonstrated a positive correlation between increased peripheral total leukocyte counts and diabetes risk [22]. Peripheral total leukocyte count is reportedly an independent risk factor for type 2 diabetes in young men at values well within the normal range, and overweight and obese subjects with relatively low peripheral total leukocyte counts seem to be at a significantly lower risk of diabetes compared with those with higher leukocyte counts [23]. Furthermore, peripheral total leukocyte count has also been associated with dyslipidemia $[24,25]$ and is suggested to be a predictor of coronary heart disease [26]. In the present study, peripheral total leukocyte and monocyte counts were significantly higher in obese young adults, and in an analysis of 23 subjects, we demonstrated that these counts were associated with serum liver enzyme, insulin resistance, and fat volume. Because of the high prevalence ( 9 out of 12 subjects) of NAFLD in the obese group, we concluded that excessive and ectopic fat deposition appears to cause early systemic inflammation, leading to the elevation of peripheral inflammatory cells such as monocytes. Therefore, obese young adults with elevated total leukocytes and monocytes may be considered for early preventive intervention.

Several reports demonstrated that obese adults and children have increased peripheral CD4+ T cells $[8,9,12,27,28]$, but not CD8+ T cells $[8,9,27]$. These results suggest a selective 
A
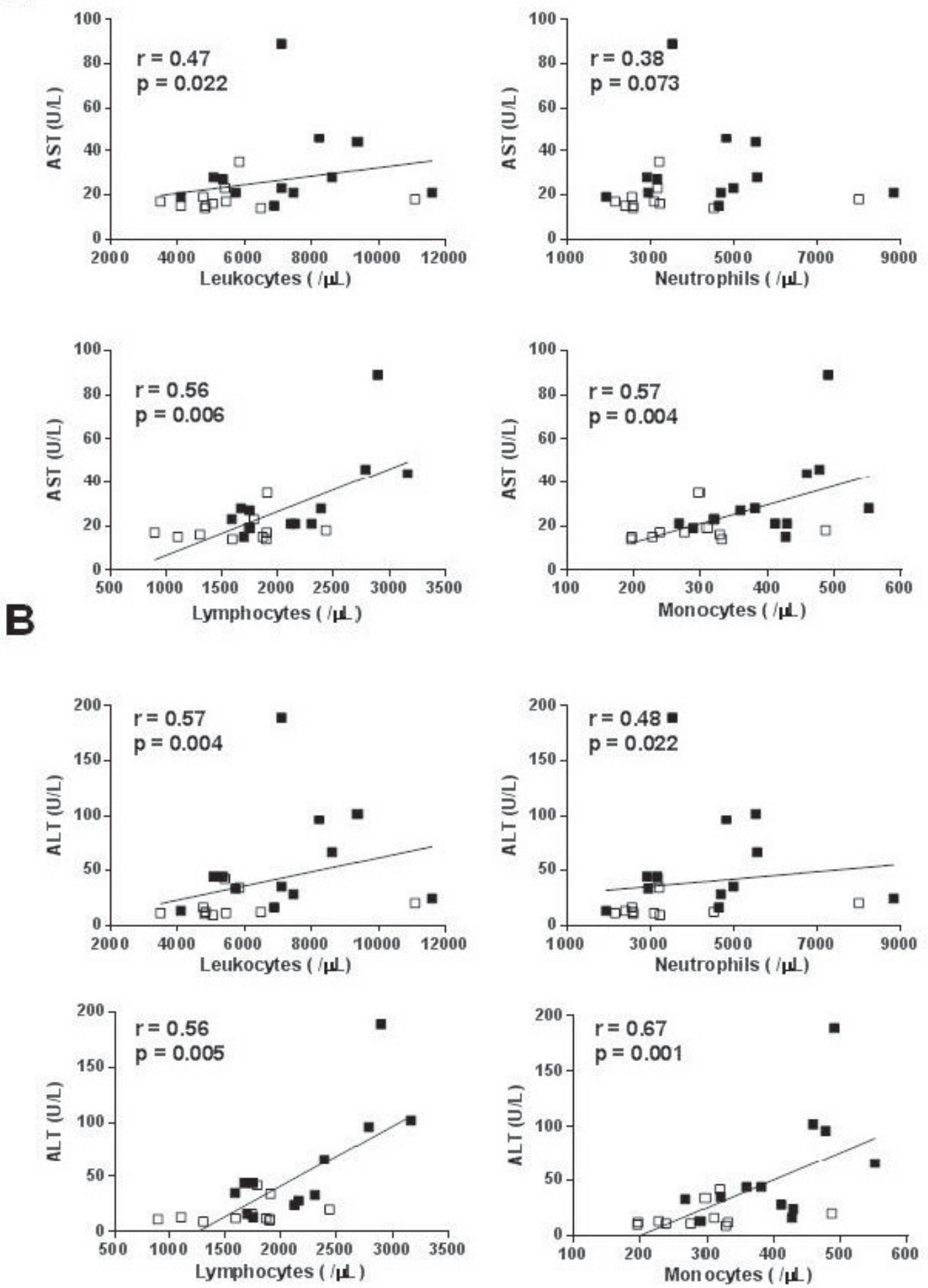

Fig. 1. Correlation of peripheral total leukocyte, neutrophil, lymphocyte and monocyte counts with serum levels of $\mathbf{A}$ aspartate aminotransferase (AST), B alanine aminotransferase (ALT), C $\gamma$-glutamyl transpeptidase $(\gamma-\mathrm{GTP})$, and $\mathbf{D}$ choline esterase (ChE). Open squares represent control subjects. Closed squares represent obese subjects

(For figure $C$, D see next page.) 
Yoshimura et al.: Association of Peripheral Total and Differential Leukocyte Counts with Obesity-Related Complications in Young Adults

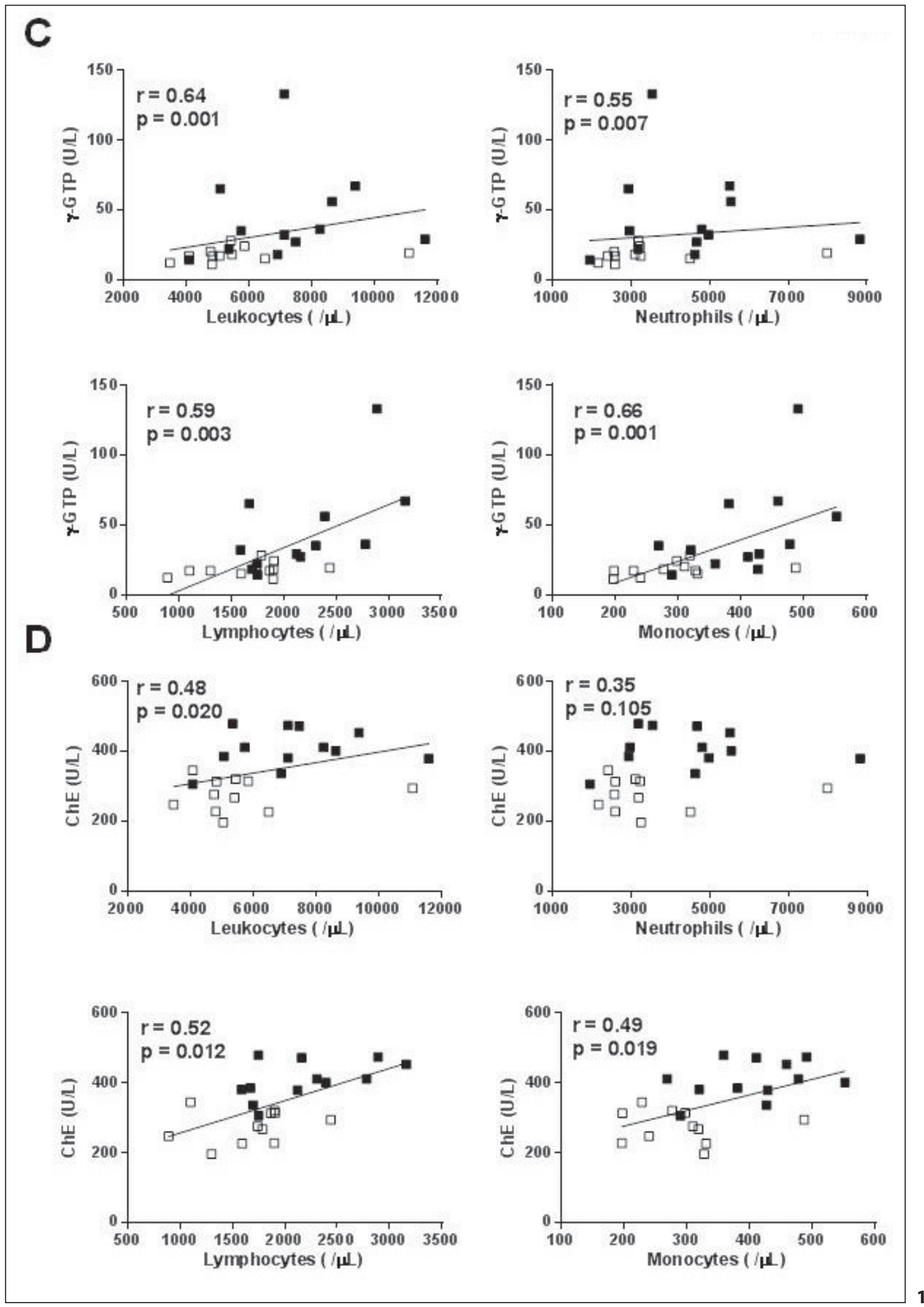


Yoshimura et al.: Association of Peripheral Total and Differential Leukocyte Counts with Obesity-Related Complications in Young Adults
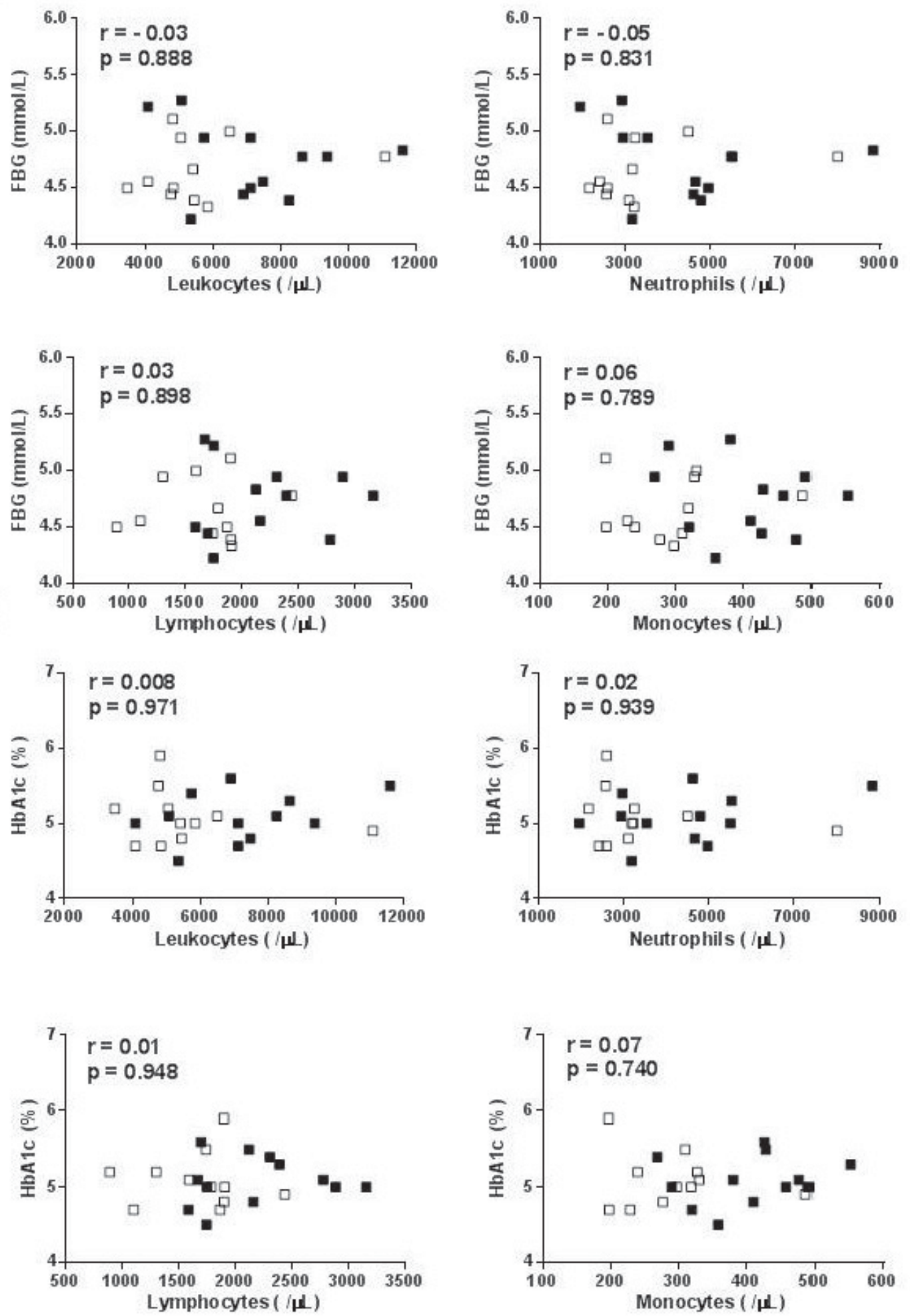

Fig. 2. Correlation of peripheral total leukocyte, neutrophil, lymphocyte and monocyte counts with $\mathbf{A}$ fasting blood glucose (FBG), B hemoglobin A1c (HbA1c), C insulin, and D homeostasis model assessment of insulin resistance (HOMA-IR). Open squares represent control subjects. Closed squares represent obese subjects. 
Yoshimura et al.: Association of Peripheral Total and Differential Leukocyte Counts with Obesity-Related Complications in Young Adults

C
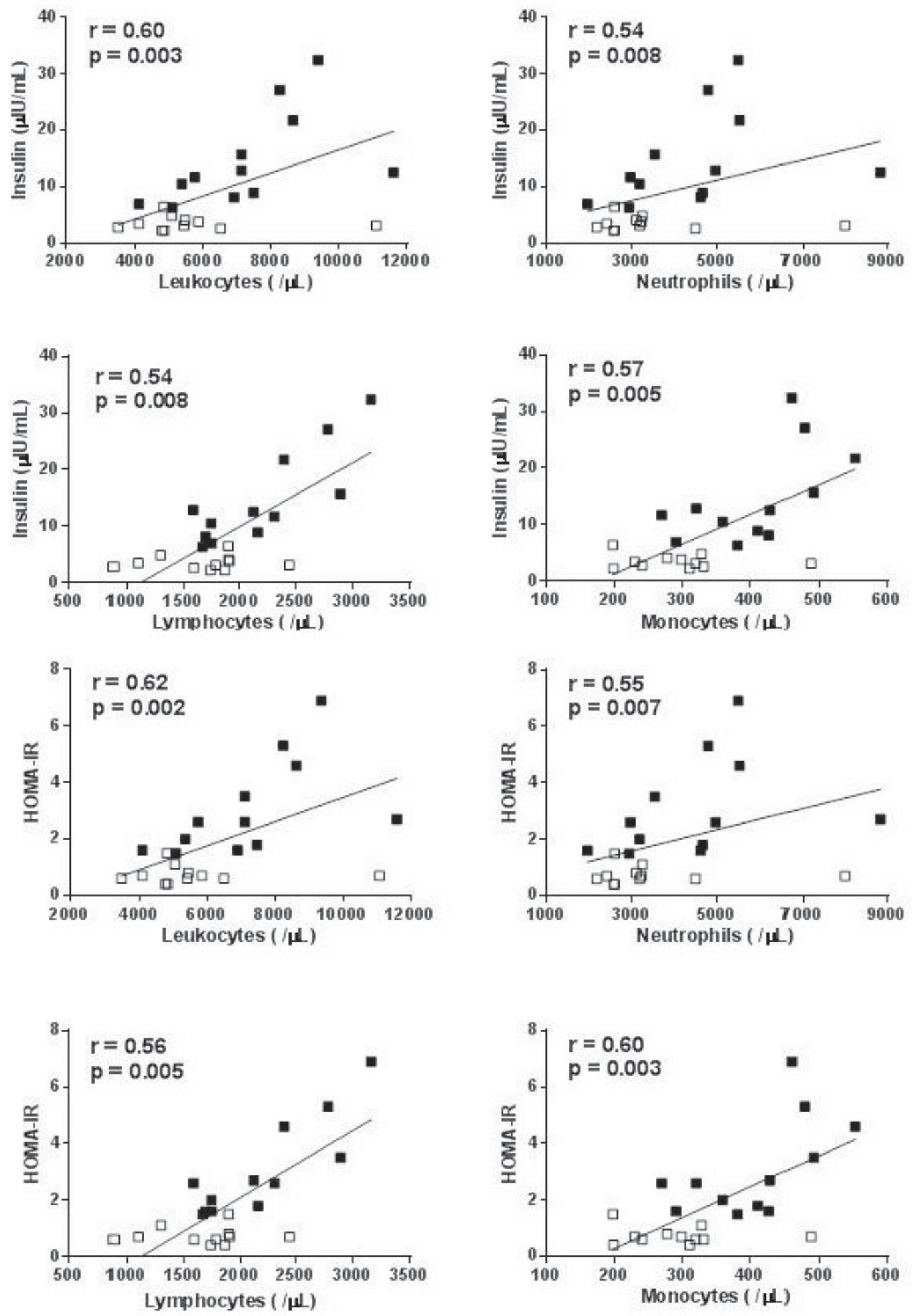
Yoshimura et al.: Association of Peripheral Total and Differential Leukocyte Counts with Obesity-Related Complications in Young Adults

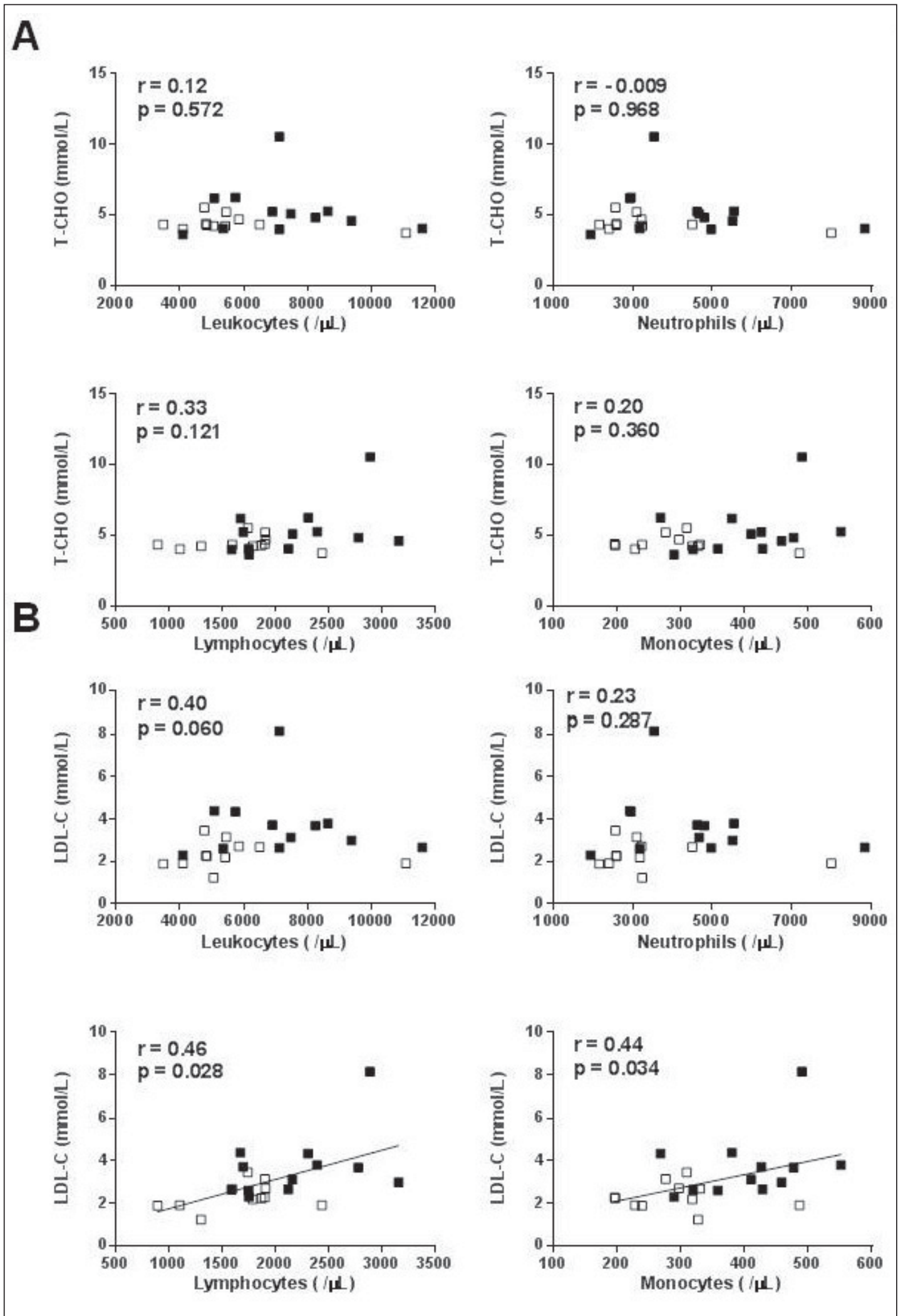

Fig. 3. Correlation of peripheral total leukocyte, neutrophil, lymphocyte and monocyte counts with $\mathbf{A}$ total cholesterol (T-CHO), B low-density lipoprotein cholesterol (LDL-C), C high-density lipoprotein cholesterol (HDL$\mathrm{C})$, and $\mathbf{D}$ triglycerides (TG). Open squares represent control subjects. Closed squares represent obese subjects. 
Yoshimura et al.: Association of Peripheral Total and Differential Leukocyte Counts with Obesity-Related Complications in Young Adults
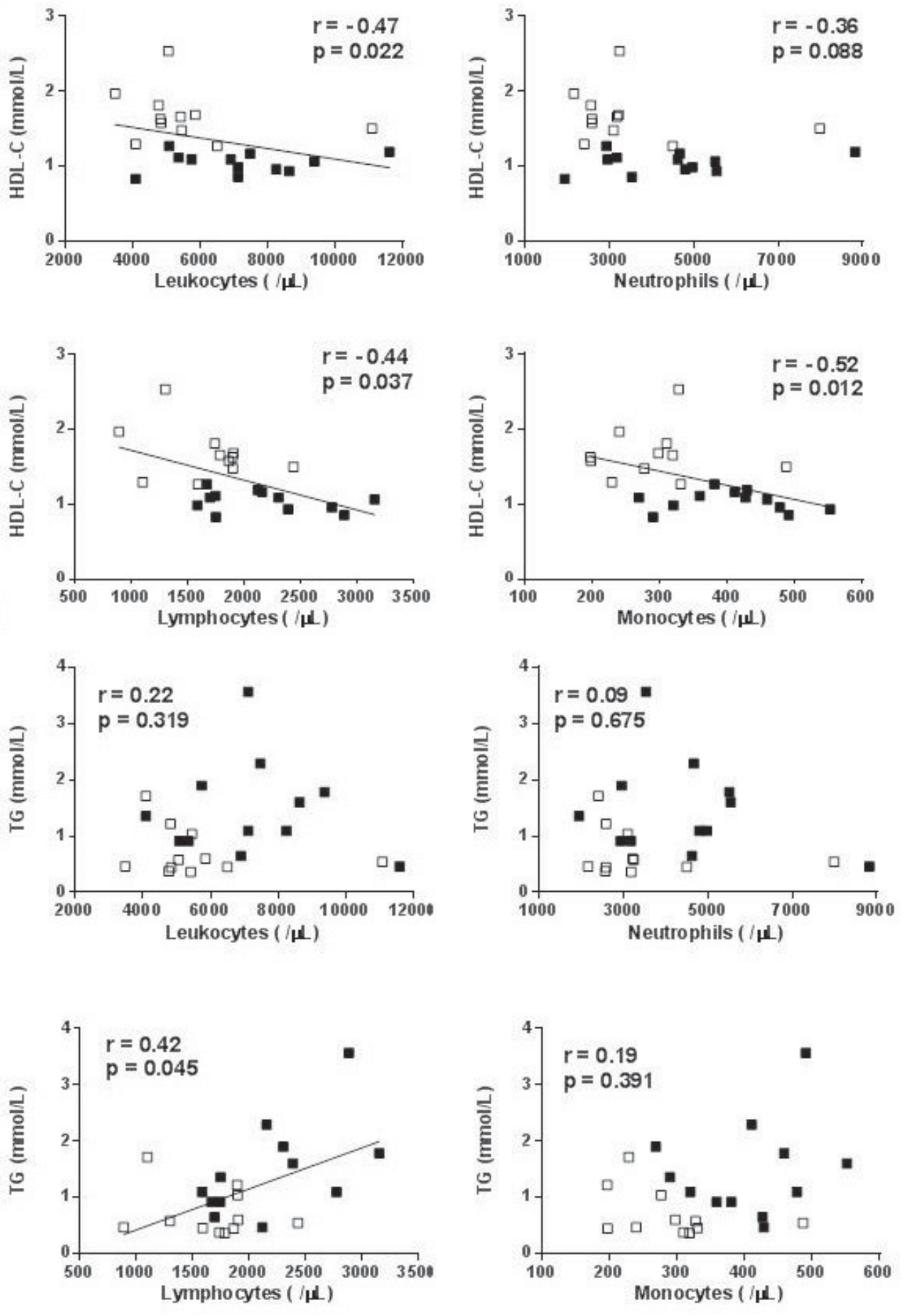
Yoshimura et al.: Association of Peripheral Total and Differential Leukocyte Counts with Obesity-Related Complications in Young Adults

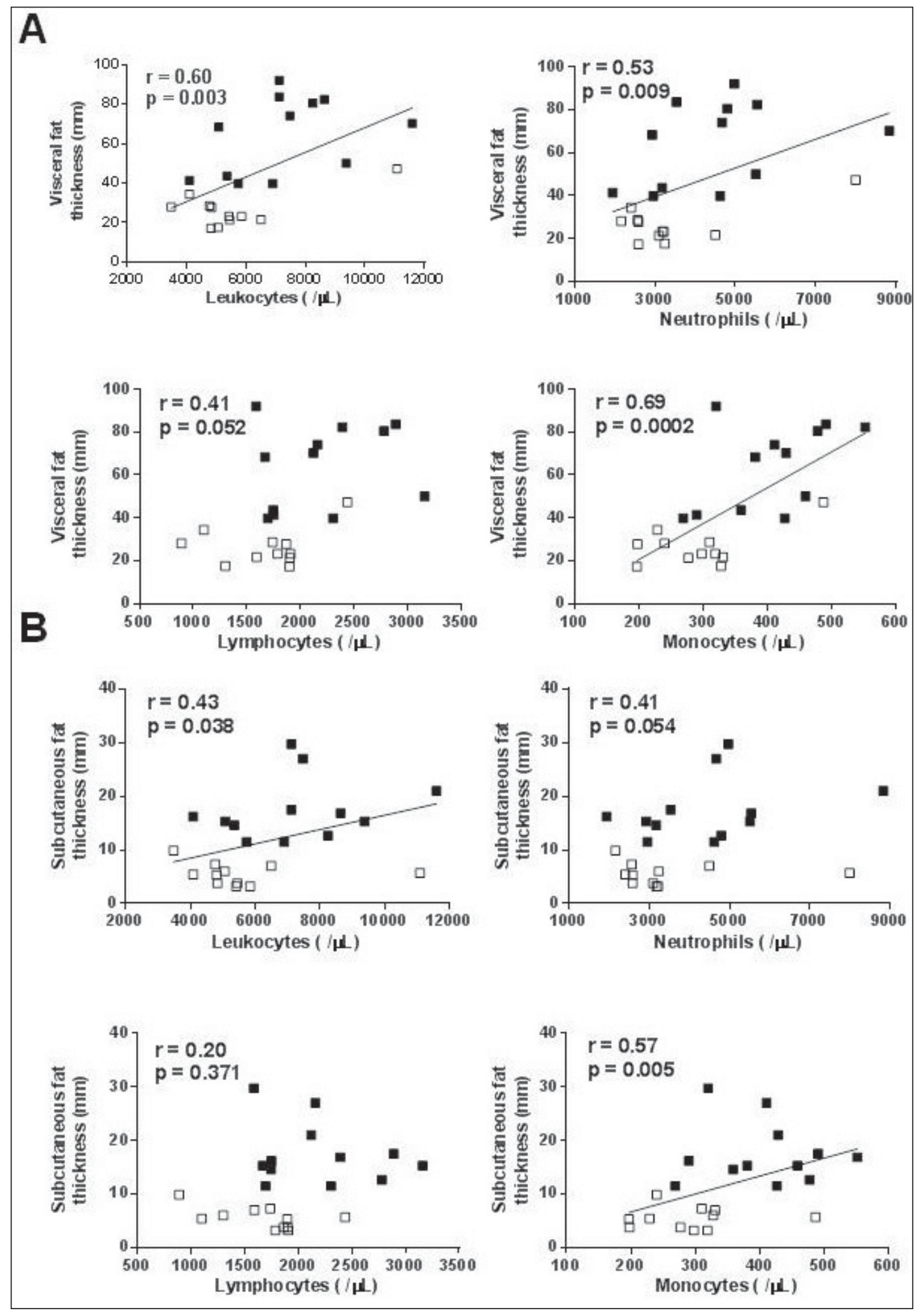

Fig. 4. Correlation of peripheral total leukocyte, neutrophil, lymphocyte and monocyte counts with $\mathbf{A}$ visceral fat thickness measured by ultrasonography, B subcutaneous fat thickness measured by ultrasonography, C body fat mass calculated by a bioimpedance analysis device, and $\mathbf{D}$ percentage body fat calculated by a bioimpedance analysis device. Open squares represent control subjects. Closed squares represent obese subjects. 
Yoshimura et al.: Association of Peripheral Total and Differential Leukocyte Counts with Obesity-Related Complications in Young Adults

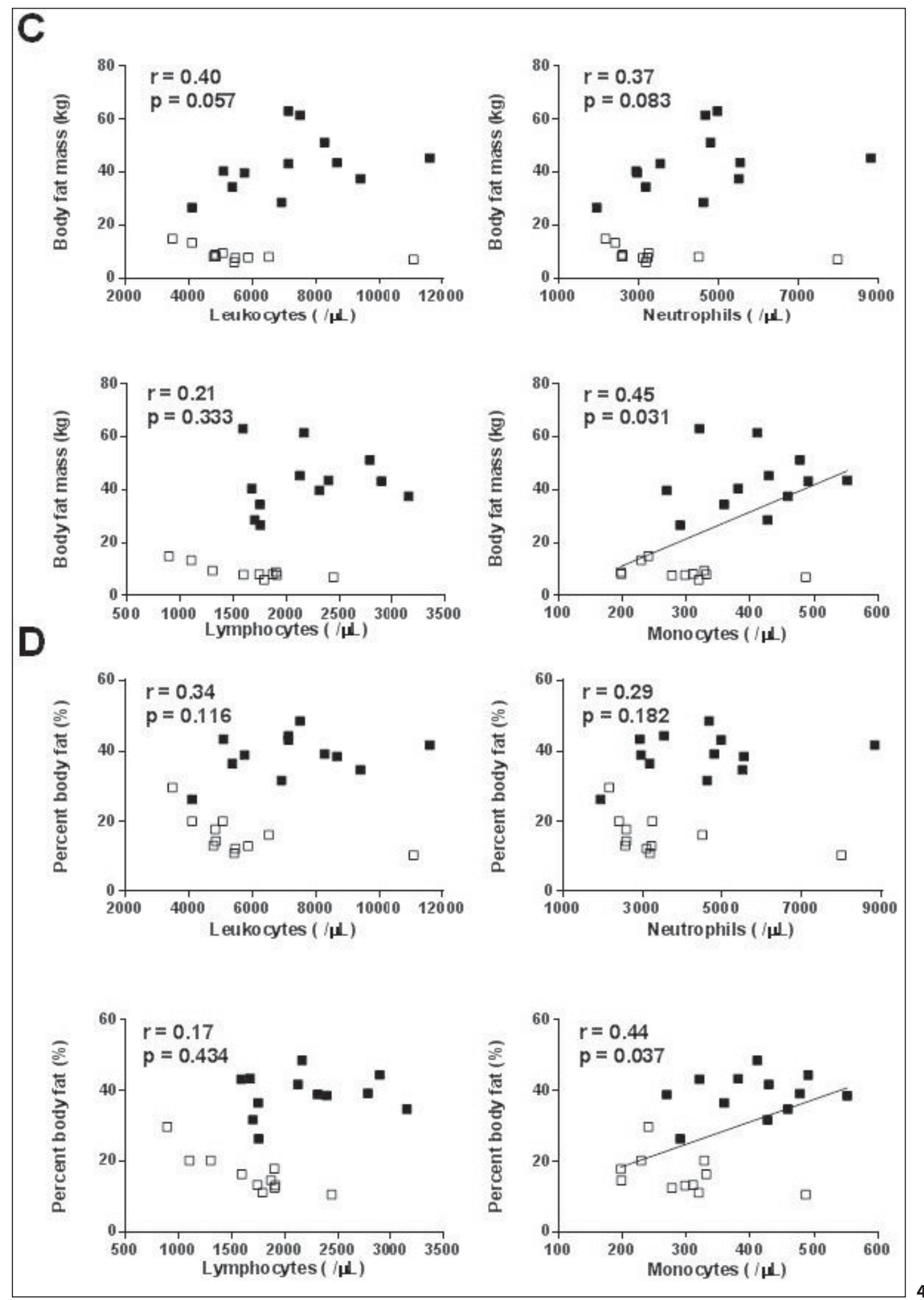


Yoshimura et al.: Association of Peripheral Total and Differential Leukocyte Counts with Obesity-Related Complications in Young Adults

redistribution of CD8+ T cells into adipose tissue [29]. In addition, patients with nonalcoholic steatohepatitis (NASH) exhibited increased numbers of peripheral CD4+ T cells and both CD4+ CD45R0+ and CD8+ CD45RO+ memory T cells, together with a higher frequency of IFN- $\gamma$-producing CD4+ and CD8+ T cells [30]. Furthermore, greater numbers and activation of CD14+ monocytes were associated with hyperglycemia and increased atherosclerosis in obese adults and children [31-34]. It has also been reported that reactive oxygen species production is increased in the peripheral monocytes of obese patients [35]. Therefore, CD4+ T cells, memory T cells, or CD14+ monocytes may be the major subtypes of increased leukocytes, although we did not measure the surface markers of peripheral leukocytes.

The influence of subcutaneous fat is more modest than that of visceral fat; however, subcutaneous fat tissue also affects the inflammatory process [36]. In the present study, peripheral monocyte count positively correlated with visceral and subcutaneous fat thickness as well as with body fat mass and percentage body fat. These results suggest that the peripheral monocyte number reflects fat volume. Because the number of subjects was limited, it was difficult to conclude that lymphocyte count was not associated with visceral or subcutaneous fat thickness. Further studies with a larger number of subjects are required to investigate this in greater depth.

In the present study, erythrocyte count was significantly higher in the obese group than in the control group. Other studies reported that higher erythrocyte count was associated with pre-diabetes, obesity, metabolic syndrome, and insulin resistance [37-39]. The activation of tyrosine kinase in the insulin receptor, which could be essential for the growthpromoting action of insulin, is widely accepted as the mechanism accounting for this finding [40].

Our study demonstrated that serum amylase levels were significantly decreased in the obese group. It has been reported that low serum amylase levels were associated with an increased risk of metabolic abnormalities, metabolic syndrome, and diabetes [41] and with NAFLD in asymptomatic adults [42]. An explanation for this relationship is systemic ectopic fat deposition in organs, including the pancreas, and studies have linked intrapancreatic fat deposition with NAFLD and metabolic syndrome [43, 44]. Systemic fat deposition in multiple organs may therefore be a common cause for NAFLD and pancreatic dysfunction, causing impaired exocrine function.

\section{Conclusions}

In conclusion, peripheral total leukocyte and monocyte counts are associated with obesity-related complications such as NAFLD, insulin resistance, and dyslipidemia in young adults; in addition, peripheral monocyte count is associated with fat volume. Given that chronic low-grade systemic inflammation contributes to morbidity and mortality, early detection of obesity in young adults and appropriate preventive intervention appear to be important. However, one limitation of the present study is the small number of subjects. Further studies with a larger number of participants will be required to corroborate our findings.

\section{Acknowledgments}

This work was supported in part by the Creation of Innovation Centers for Advanced Interdisciplinary Research Areas Program of the Ministry of Education, Culture, Sports, Science and Technology, Japan. We thank Koji Oba for statistical analysis, and the participating students for their co-operation. 
Yoshimura et al.: Association of Peripheral Total and Differential Leukocyte Counts with Obesity-Related Complications in Young Adults

\section{Disclosure Statement}

The authors declare no conflicts of interest.

\section{References}

1 Lee JM: Why young adults hold the key to assessing the obesity epidemic in children. Arch Pediatr Adolesc Med 2008;162:682-687.

2 Das UN: Obesity: genes, brain, gut, and environment. Nutrition 2010;26:459-473.

-3 Moulin CM, Marguti I, Peron JP, Rizzo LV, Halpern A: Impact of adiposity on immunological parameters. Arq Bras Endocrinol Metabol 2009;53:183-189.

-4 Sell H, Eckel J: Adipose tissue inflammation: novel insight into the role of macrophages and lymphocytes. Curr Opin Clin Nutr Metab Care 2010;13:366-370.

5 Gregor MF, Hotamisligil GS: Inflammatory mechanisms in obesity. Annu Rev Immunol 2011;29:415-445.

-6 Schwartz J, Weiss ST: Host and environmental factors influencing the peripheral blood leukocyte count. Am J Epidemiol 1991;134:1402-1409.

7 Nieto FJ, Szklo M, Folsom AR, Rock R, Mercuri M: Leukocyte count correlates in middle-aged adults: the Atherosclerosis Risk in Communities (ARIC) Study. Am J Epidemiol 1992;136:525-537.

8 Womack J, Tien PC, Feldman J, Shin JH, Fennie K, Anastos K, Cohene MH, Baconf MC, Minkoff H: Obesity and immune cell counts in women. Metabolism 2007;56:998-1004.

-9 Nieman DC, Henson DA, Nehlsen-Cannarella SL, Ekkens M, Utter AC, Butterworth DE, Fagoaga OR: Influence of obesity on immune function. J Am Diet Assoc 1999;99:294-299.

10 Kim JA, Park HS: White blood cell count and abdominal fat distribution in female obese adolescents. Metabolism 2008;57:1375-1379.

-11 Panagiotakos DB, Pitsavos C, Yannakoulia M, Chrysohoou C, Stefanadis C: The implication of obesity and central fat on markers of chronic inflammation: The ATTICA study. Atherosclerosis 2005;183:308-315.

-12 Zaldivar F, McMurray RG, Nemet D, Galassetti P, Mills PJ, Cooper DM: Body fat and circulating leukocytes in children. Int J Obes (Lond) 2006;30:906-911.

13 Visser M, Bouter LM, McQuillan GM, Wener MH, Harris TB: Low-grade systemic inflammation in overweight children. Pediatrics 2001;107:E13.

14 Veronelli A, Laneri M, Ranieri R, Koprivec D, Vardaro D, Paganelli M, Folli F, Pontiroli AE: White blood cells in obesity and diabetes: effects of weight loss and normalization of glucose metabolism. Diabetes Care 2004;27: 2501-2502.

15 Kullo IJ, Hensrud DD, Allison TG: Comparison of numbers of circulating blood monocytes in men grouped by body mass index $(<25,25$ to $<30$, $>$ or=30). Am J Cardiol 2002;89:1441-1443.

16 Matthews DR, Hosker JP, Rudenski AS, Naylor BA, Treacher DF, Turner RC: Homeostasis model assessment: insulin resistance and beta-cell function from fasting plasma glucose and insulin concentrations in man. Diabetologia 1985;28:412-419.

17 Lorenzo AD, Andreoli A: Segmental bioelectrical impedance analysis. Curr Opin Clin Nutr Metab Care 2003;6: 551-557.

18 Armellini F, Zamboni M, Rigo L, Todesco T, Bergamo-Andreis IA, Procacci C: The contribution of sonography to the measurement of intra-abdominal fat. J Clin Ultrasound 1990;18:563-567.

19 Yajima Y, Ohta K, Narui T, Abe R, Suzuki H, Ohtsuki M: Ultrasonographical diagnosis of fatty liver: significance of the liver-kidney contrast. Tohoku J Exp Med 1983;139:43-50.

20 Lee YJ, Lee HR, Shim JY, Moon BS, Lee JH, Kim JK: Relationship between white blood cell count and nonalcoholic fatty liver disease. Dig Liver Dis 2010;42:888-894.

-21 Kim HL, Chung GE, Park IY, Choi JM, Hwang SM, Lee JH, Kim D: Elevated peripheral blood monocyte fraction in nonalcoholic fatty liver disease. Tohoku J Exp Med 2011;223:227-233.

22 Gkrania-Klotsas E, Ye Z, Cooper AJ, Sharp SJ, Luben R, Biggs ML, Chen LK, Gokulakrishnan K, Hanefeld M, Ingelsson E, Lai WA, Lin SY, Lind L, Lohsoonthorn V, Mohan V, Muscari A, Nilsson G, Ohrvik J, Qiang JC, Jenny NS, Tamakoshi K, Temelkova-Kurktschiev T, Wang YY, Yajnik CS, Zoli M, Khaw KT, Forouhi NG, Wareham NJ, Langenberg C: Differential white blood cell count and type 2 diabetes: systematic review and meta-analysis of cross-sectional and prospective studies. PLoS One 2010;5:e13405.

23 Twig G, Afek A, Shamiss A, Derazne E, Tzur D, Gordon B, Tirosh A: White blood cells count and incidence of type 2 diabetes in young men. Diabetes Care 2013;36:276-282.

-24 Hansen LK, Grimm RH, Neaton JD: The relationship of white blood cell count to other cardiovascular risk factors. Int J Epidemiol 1990;19:881-888.

25 Friedman GD, Tekawa I, Grimm RH, Manolio T, Shannon SG, Sidney S: The leucocyte count: correlates and relationship to coronary risk factors: the CARDIA study. Int J Epidemiol 1990;19:889-893.

26 Brown DW, Giles WH, Croft JB: White blood cell count: an independent predictor of coronary heart disease mortality among a national cohort. J Clin Epidemiol 2001;54:316-322. 
Yoshimura et al.: Association of Peripheral Total and Differential Leukocyte Counts with Obesity-Related Complications in Young Adults

27 van der Weerd K, Dik WA, Schrijver B, Schweitzer DH, Langerak AW, Drexhage HA, Kiewiet RM, van Aken MO, van Huisstede A, van Dongen JJM, van der Lelij AJ, Staal FJT, van Hagen PM: Morbidly obese human subjects have increased peripheral blood CD4+ T cells with skewing toward a Treg- and Th2-dominated phenotype. Diabetes 2012;61:401-408.

28 O’Rourke RW, Kay T, Scholz MH, Diggs B, Jobe BA, Lewinsohn DM, Bakke AC: Alterations in T-cell subset frequency in peripheral blood in obesity. Obes Surg 2005;15:1463-1468.

29 Nishimura S, Manabe I, Nagasaki M, Eto K, Yamashita H, Ohsugi M, Otsu M, Hara K, Ueki K, Sugiura S, Yoshimura K, Kadowaki T, Naga R: CD8+ effector T cells contribute to macrophage recruitment and adipose tissue inflammation in obesity. Nat Med 2009;15:914-920.

-30 Inzaugarat ME, Ferreyra Solari NE, Billordo LA, Abecasis R, Gadano AC, Cherñavsky AC: Altered phenotype and functionality of circulating immune cells characterize adult patients with nonalcoholic steatohepatitis. J Clin Immunol 2011;31:1120-1130.

-31 Poitou C, Dalmas E, Renovato M, Benhamo V, Hajduch F, Abdennour M, Kahn JF, Veyrie N, Rizkalla S, Fridman WH, Sautès-Fridman C, Clément K, Cremer I: CD14dimCD16+ and CD14+CD16+ monocytes in obesity and during weight loss: relationships with fat mass and subclinical atherosclerosis. Arterioscler Thromb Vasc Biol 2011;31:2322-2330.

-32 Rogacev KS, Ulrich C, Blömer L, Hornof F, Oster K, Ziegelin M, Cremers B, Grenner Y, Geise J, Schlitt A, Köhler H, Fliser D, Girndt M, Heine GH: Monocyte heterogeneity in obesity and subclinical atherosclerosis. Eur Heart J 2010;31:369-376.

33 Satoh N, Shimatsu A, Himeno A, Sasaki Y, Yamakage H, Yamada K, Suganami T, Ogawa Y: Unbalanced M1/M2 phenotype of peripheral blood monocytes in obese diabetic patients: effect of pioglitazone. Diabetes Care 2010;33:e7.

-34 Schipper HS, Nuboer R, Prop S, van den Ham HJ, de Boer FK, Kesmir C, Mombers IMH, van Bekkum KA, Woudstra J, Kieft JH, Hoefer IE, de Jager W, Prakken B, van Summeren M, Kalkhoven E: Systemic inflammation in childhood obesity: circulating inflammatory mediators and activated CD14++ monocytes. Diabetologia 2012;55:2800-2810.

-35 Degasperi GR, Denis RG, Morari J, Solon C, Geloneze B, Stabe C, Pareja JC, Vercesi AE, Velloso LA: Reactive oxygen species production is increased in the peripheral blood monocytes of obese patients. Metabolism 2009;58:1087-1095.

-36 Fried SK, Bunkin DA, Greenberg AS: Omental and subcutaneous adipose tissues of obese subjects release interleukin-6:depot difference and regulation by glucocorticoid. J Clin Endocrinol Metab 1998;83:847-850. Simmons D: Increased red cell count in diabetes and pre-diabetes. Diabetes Res Clin Pract 2010;90:e50-53.

-38 Hanley AJ, Retnakaran R, Qi Y, Gerstein HC, Perkins B, Raboud J, Harris SB, Zinamn B: Association of hematological parameters with insulin resistance and beta-cell dysfunction in nondiabetic subjects. J Clin Endocrinol Metab 2009;94:3824-3832.

-39 Barbieri M, Ragno E, Benvenuti E, Zito GA, Corsi A, Ferrucci L, Paolisso G: New aspects of the insulin resistance syndrome: impact on haematological parameters. Diabetologia 2001;44:1232-1237.

40 Wang LM, Myers MG, Sun XJ, Aaronson SA, White M, Pierce JH: IRS-1:essential for insulin- and IL-4-stimulated mitogenesis in hematopoietic cells. Science 1993;261:1591-1594.

41 Nakanishi N, Sato M, Shirai K, Nakajima K, Murakami S, Takatorige T, Suzuki K, Tatara K: Associations between white blood cell count and features of the metabolic syndrome in Japanese male office workers. Ind Health 2002;40:273-277.

42 Nakajima K, Nemoto T, Muneyuki T, Kakei M, Fuchigami H, Munakata H: Low serum amylase in association with metabolic syndrome and diabetes: a community-based study. Cardiovasc Diabetol 2011;10:34.

43 van Geenen EJ, Smits MM, Schreuder TC, van der Peet DL, Bloemena E, Mulder CJ: Nonalcoholic fatty liver disease is related to nonalcoholic fatty pancreas disease. Pancreas 2010;39:1185-1190.

-44 Sepe PS, Ohri A, Sanaka S, Berzin TM, Sekhon S, Bennett G, Mehta G, Chuttani R, Kane R, Pleskow D, Sawhney MS: A prospective evaluation of fatty pancreas by using EUS. Gastrointest Endosc 2011;73:987-993. 